$12-2012$

\title{
Attentional Biases to Foods: The Effects of Caloric Content and Cognitive Restraint
}

\author{
Catherine A. Forestell \\ William \& Mary, caforestell@wm.edu
}

Pia Lau

Ivo I. Gyurovski

Cheryl L. Dickter

William \& Mary, cldickter@wm.edu

Sabrina S. Haque

Follow this and additional works at: https://scholarworks.wm.edu/aspubs

Part of the Health Psychology Commons

\section{Recommended Citation}

Forestell, Catherine A.; Lau, Pia; Gyurovski, Ivo I.; Dickter, Cheryl L.; and Haque, Sabrina S., Attentional Biases to Foods: The Effects of Caloric Content and Cognitive Restraint (2012). Appetite, 59(3), 748-754. https://doi.org/10.1016/j.appet.2012.07.006

This Article is brought to you for free and open access by the Arts and Sciences at W\&M ScholarWorks. It has been accepted for inclusion in Arts \& Sciences Articles by an authorized administrator of W\&M ScholarWorks. For more information, please contact scholarworks@wm.edu. 


\title{
Attentional biases to foods. The effects of caloric content and cognitive restraint
}

\author{
4 Q1 Catherine A. Forestell a,*, Pia Lau ${ }_{\Lambda}^{a, b}$, Ivo I. Gyurovski a, Cheryl L. Dickter ${ }_{\Lambda}^{a}$, Sabrina A. Haque $_{\Lambda}^{a}$ \\ 5 a Department of Psychology, The College of Mary, P.O. Box 8795, Williamsburg, VA 23187-8795, USA \\ 6 Q2 ${ }^{\mathrm{b}}$ Westfälische Wilhelms-Universität, Münster, Germany
}

7

29

11

12

13

15

\begin{abstract}
A B S T R A C T
The goal of the present study was to determine whether female participants demonstrated differential levels of attentional bias to high calorie foods when they were presented as distractors in a flanker task as a function of their cognitive restraint. This task consisted of four blocks of 68 trials in which three food pictures were briefly presented simultaneously on a computer screen. On each trial a high or low calorie target food was presented in the center of a pair of high or low calorie food flanker pictures and participants' reaction times to answer a basic question about whether they would consume the target food for breakfast were recorded. In Experiment 1, in which all participants were fed a snack prior to engaging in the flanker task, there was no evidence that restrained $(n=29)$ or unrestrained $(n=37)$ eaters had an attentional bias. However, in Experiment 2, when participants completed the flanker task while hungry, restrained eaters $(n=27)$ experienced response conflict only when low calorie targets were flanked by high calorie distractors, whereas unrestrained eaters $(n=46)$ were distracted by high calorie flankers regardless of the caloric content of the target cue. The results from this implicit task indicate that when hungry, restrained and unrestrained eaters are distracted by high calorie flankers that attenuate their performance. Whether attentional bias to food cues subsequently affects food choices and eating behavior is a topic for further investigation.
\end{abstract}

(c) 2012 Published by Elsevier Ltd.
Although food is essential for survival, many individuals find it difficult to balance the pleasure derived from eating palatable, high calorie foods and maintaining control over their body weight. According to recent findings, 68\% of the American population is overweight (Flegal, Carroll, Ogden, \& Curtin, 2010) and one third of these overweight individuals (i.e., more than 71 million inhabitants) are obese (Centers for Disease Control and Prevention, 2009). These findings are alarming given that the health risks of obesity are far-reaching (U.S. Department of Health and Human Services, 2004). Each year $\$ 147$ billion is spent on obesity-related medical costs, such as direct treatment or morbidity (Centers for Disease Control and Prevention, 2009). Many attempt to avoid these negative consequences by maintaining or reducing their weight through dieting behaviors (Williamson, Serdula, Anda, Levy, \& Byers, 1992).

According to set point theory (Herman \& Mack, 1975), the body strives to maintain weight and body fat level at a certain point, which varies between individuals, through internal regulatory controls. Given the emphasis in the media about the importance of a slim figure, those who have high set-points may be motivated to lose weight so that their bodies correspond to the dominant cultural view of a perfect body. In order to maintain a slim appearance,

\footnotetext{
* Corresponding author.

E-mail address: caforestell@wm.edu (C.A. Forestell).
}

they continually battle against their biologically determined setpoint. This conscious effort to restrict intake of certain types of foods in order to reduce one's current weight or avoid weight gain defines restrained eating (Herman \& Polivy, 1975). Over time restrained eaters eventually become less sensitive to their body's hunger and satiety cues. Therefore, regardless of whether their body is in need of calories, food intake is driven by cognitions about how the caloric and fat content of the food available will affect their weight. However, despite their efforts, many restrained eaters are generally unsuccessful in their attempt to lose weight due to their disinhibited food intake, which occurs in a variety of experimental situations that limit self-regulatory resources (see Stroebe, 2008 for a review)

Restrained eaters may thus make a conscious effort to control their attention and responses to food-related cues without success. In fact, their attempts to direct their attention away from certain food-related items may instead increase their attention to such items. According to Wegner's Ironic Process Theory (Wegner, 1994), an individual's deliberate attempt to suppress or avoid certain thoughts can cause these thoughts to become more persistent. Support for this hypothesis has been somewhat mixed with restrained eaters. For example, Stewart and Samoluk (1997) found that restrained eaters demonstrate an attentional bias for appetitive food words relative to control words in the modified Stroop task unlike unrestrained participants who failed to exhibit a bias. 
These findings suggest that chronic dietary restraint is associated with a reduced ability to direct attention away from food-related cues, highlighting the inevitable distraction food cues can have on restrained eaters. Alternatively, other research has demonstrated that in some situations, restrained eaters may be successful in directing their attention away from food-related cues (Hollitt, Kemps, Tiggemann, Smeets, \& Mills, 2010; Papies, Stroebe, \& Aarts, 2008). These findings have been qualified by other research that has failed to find that cognitive restraint is related to attentional biases for food (Ahern, Field, Yokum, Bohon, \& Stice, 2010; Boon, Vogelzang, \& Jansen, 2000). Because of the variety of methodologies used in the aforementioned studies, conflicting results may be the result of variability in task parameters, specific characteristics of the food cues, or motivational variables, such as baseline hunger levels of the participants.

Despite these inconsistent results, it is possible that restrained eaters experience difficulty with executive control in the presence of food-related cues and as a result, have difficulty filtering out competing information (e.g., healthfulness vs. palatability) from foods. The flanker task has been widely used to assess the degree to which attention is spontaneously drawn to distractor cues (Eriksen \& Eriksen, 1974). In this paradigm, participants respond to a target letter presented among a string of flanker letters that are either the same as the target (i.e., compatible) or different from the target (i.e., incompatible). Although participants are instructed to attend only to the target stimuli and ignore the flanker stimuli, they often cannot direct their attention away from the flankers. Because of the processing conflict elicited by the incompatible flankers, participants respond more slowly to incompatible trials than to compatible trials (Coles, Gratton, Bashore, Eriksen, \& Donchin, 1985; Eriksen \& Eriksen, 1974).

More recently, the flanker and other executive control paradigms have been modified to include a variety of stimulus properties of interest to test specific hypotheses. For example, Meule, Vögele, and Kübler (2012), presented target and flanker pictures of high calorie foods or neutral items in a flanker task. When participants were asked to indicate whether the target was a food or a neutral item, they found that participants were slower to respond in the incompatible trials when the target picture was a food item. In addition, restrained eaters responded faster to food targets relative to neutral targets regardless of the characteristics of the flanker. Thus, this study failed to demonstrate evidence that the high calorie flankers served to distract the restrained eaters' attention from categorizing the neutral target cue. It is possible, however, that this task was not sensitive enough to detect implicit differences in attentional bias, either because the reaction times measured in this study represented the outcome of a conscious categorization decision (Ito \& Cacioppo, 2000) or because the control pictures were not food items. Therefore, there was no way to determine whether restrained and unrestrained eaters responses differed as a function of the caloric content of the food. Further, it may have also been the case that the high calorie flankers only commanded the attention of those restrained eaters who were hungry and were thus motivated to attend to these stimuli.

The goal of the present set of studies was to expand on the research of Meule et al. (2012), to explore whether restrained eaters' attention to high and low calorie targets is distracted by high and low calorie flankers relative to unrestrained eaters when they are either fed (Experiment 1), or not fed (Experiment 2) before the task. We used a modified version of the flanker task to assess conflict between prepotent stimulus features that are not directly related to the task and attributes that are important for adaptive task performance (Botvinick, Braver, \& Barch, 2001; Dickter \& Bartholow, 2007). In Experiment 1, it was hypothesized that there would be differences in the processing of food cues in restrained and unrestrained eaters. Because the three displayed pictures create a competitive environment, cognitive control is required to focus on the target and ignore the flanker pictures. We hypothesized that restrained eaters would be more likely to be distracted by high compared to low calorie flankers while completing the task. However, no such difference should be observed in unrestrained eaters.

\section{Experiment 1}

Method

\section{Participants}

The participants $(N=88)$ were undergraduate female students $\mathbf{Q} 3163$ of the College of William and Mary, Virginia, USA. Twenty-four percent had been recruited through flyers posted on campus and paid $\$ 10$ for their participation between the spring semesters of 2010 and 2011. The remaining students were taking Introduction to Psychology classes and received credit for their participation. In order to standardize hunger levels, all participants were asked to refrain from eating for $2 \mathrm{~h}$ before arriving at the lab for their scheduled appointment which occurred between 8 and $11 \mathrm{am}$.

Measures/materials

\section{Pre-test meal}

Participants were fed a small snack which consisted of one granola bar (chocolate caramel protein \& fiber bar or TLC chewy granola bars from Kashic), which ranged from 140-150 Cal) and a juice (apple or mixed berry juice from Minute Maid $\odot, 100$ Cal).

\section{Picture stimuli}

Sixty-eight color pictures of foods were used as stimuli. Approximately half of the foods were highly processed, high calorie and/or high fat foods, such as chocolate, French fries, or croissants (ranging from 140-430 Cal/serving), while the remaining foods were low calorie and/or low fat foods such as fruit, vegetables, whole grains, legumes, or fish (ranging from 2-130 Cal/serving). Foods within the low calorie category that were relatively higher in caloric value (e.g., corn) were low in fat, whereas those foods in the high calorie category that were lower in caloric value (e.g., bologna) were high in fat. Half of the pictures in each of these categories depicted foods that are commonly eaten at breakfast by Americans (e.g., oranges, yogurt, croissants, donuts, etc.). All picture stimuli may be obtained by contacting the corresponding author.

For each picture, the food was placed on a white square plate with a black background behind it and the camera was positioned about $90 \mathrm{~cm}$ away from the food item. To determine whether these foods were recognizable to participants, a pilot study with 16 participants was conducted. The food pictures were briefly displayed on the screen for $250 \mathrm{~ms}$ and participants were asked to identify the food in the picture. Pictures were programmed with E-Prime 2.0 (Psychology Software Tools, Inc., 2007) on a 17-inch monitor. On average, participants recognized $93 \%$ of the foods. One picture (red beans) was eliminated because the majority of the participants in the pilot study failed to correctly identify this food.

\section{Flanker task}

As for the pilot task, the flanker task was programmed using E-Prime 2.0 on a 17-inch monitor. Each trial comprised of a prestimulus baseline during which a fixation cross was presented in the middle of the screen for 1000 ms. This was followed by a stimulus array which consisted of one target picture with two pictures on either side of the target (i.e., flankers) for $250 \mathrm{~ms}$ followed by a blank screen. Flanker and target pictures were randomly drawn from the same set of high and low calorie photographs, with the 
restriction that the flanker pictures were always identical to one another but different from the target picture and that four types of trials appeared randomly with equal probability (17 times each) and consisted of the following picture arrays; (1) the target and flanker pictures were all high calorie foods $(\mathrm{HHH}),(2)$ the target was a high calorie picture, flanked by two low caloric pictures (LHL), (3) the target was a low caloric picture and the flanker was high caloric (HLH), and (4) all pictures displayed were low calorie foods (LLL). Intertrial intervals varied randomly from 1000 to $3000 \mathrm{~ms}$ to avoid time conditioning. On each trial participants were asked to indicate whether the target food was a "food that they would eat for breakfast by pressing one of two keys on the keyboard." They were instructed to respond as quickly as possible and focus only on the middle (i.e., target) picture. Each participant completed four blocks of 68 trials.

\section{Questionnaires}

In addition to answering individual questions about their demographics (age, race and ethnic background), their present hunger (measured on a Likert scale from 1 to 7 , with "not at all hungry" (1), and "very hungry" (7) as anchors), height, weight, and food allergies, we also asked participants to complete a series of standardized questionnaires which assessed their daily eating behavior. These questionnaires are described below.

The Three Factor Eating Questionnaire (TFEQ; Stunkard \& Messick, 1985) was distributed to assess restrained eating behavior of the participants. It allows a close analysis of eating behavior in general as it covers restraint, disinhibition, and susceptibility to hunger. This explicit differentiation between restraint and disinhibition sets this scale apart from other scales measuring restrained eating, like the Herman and Polivy Restraint Scale (1980). Westenhoefer, Broeckmann, Münch, and Pudel (1994) have shown that this discrimination between restrained and disinhibited eaters is necessary to explain different eating behaviors, e.g., counter-regulation after preload. In the present study, the restraint subscale of this questionnaire was used to assign participants to restraint groups. Internal consistency $(\alpha=.90)$ and test-retest reliability $(r=.91)$ have been shown to be adequate for this measure.

\section{Food Neophobia (FN)}

Pliner and Hobden-1992) operationalized the concept of Food Neophobia with 10 items that included questions such as "I am afraid to eat things I never had before" and "I don't trust new foods". Participants were asked to respond using a 7-point scale with one indicating disagreement and seven agreement. This measure has been shown to have good internal consistency (Chronbach $\alpha=.86)$ and test-retest reliability $(r=0.81)$. Although not considered a primâry measure in the present study, Food Neophobia was collected to ensure that restrained and unrestrained eaters did not differ on these constructs.

\section{Procedure}

Participants arrived at the lab individually for their scheduled appointment. After signing the informed consent form, the participants were given their pre-test meal and asked to finish the juice and granola bar provided in order to attain standardized conditions. Participants were then asked to complete the demographic questionnaire described above. Twenty minutes after the participants had finished eating they were taken to another room where they rated their hunger and completed the flanker task. During the flanker task, participants sat at a computer, $90 \mathrm{~cm}$ away from the screen, yielding a visual angle of about $30^{\circ}$. As the participant completed the flanker task, the researcher was approximately $1.5 \mathrm{~m}$ away from and not facing the participant. Questionnaires covering food and eating behavior explicitly (TFEQ and FN) were completed after the flanker task, followed by the measurement of weight and height in a separate room. On average, the entire procedure took 70 min to complete. All procedures were approved by the College of William and Mary Protection of Human Subjects Committee.

\section{Data analyses}

Participants were divided into restraint groups based on their score on the restraint portion of the TFEQ. Those scoring 11 or above were designated as "restrained eaters".

For each participant, individual trials on the flanker task with reaction times deviating three standard deviations from the mean were discarded as is common practice in the analysis of reaction time paradigms. Mean reaction times were calculated for each of the 3-picture array combinations (i.e., HHH, HLH, LHL, and LLL) for each participant. To determine whether restrained and nonrestrained eaters' response times differed between these stimulus arrays, we used a mixed 3-way Analysis of Variance (ANOVA) with the between-subjects variable of restraint group (restrained $v s$. unrestrained), and the repeated measures variables of target picture (high $v s$. low calorie) and flanker picture (high vs. low calorie) and the dependent variable of response time.

Results

\section{Participant characteristics}

Participants who were missing reaction time data $(n=2)$, had average latencies over $900 \mathrm{~ms}(n=8)$, major food allergies (e.g., lactose, red meat, shellfish, tomatoes; $n=11$ ), or were vegetarian $(n=1)$ were excluded from analyses. Of the remaining 66 participants, 9.1\% were Hispanic or Latino, and their racial background consisted of $80 \%$ White, $8 \%$ African American, and 12\% Asian women who were on average $19.2(\mathrm{SEM} \pm 0.2)$ years old and had a BMI of $22.5( \pm 0.5)$. Based on their scores on the restrained eating scale, participants were divided into restrained $(n=29)$ and unrestrained $(n=37)$ in the manner described in above. As shown in Table 1 , the mean restraint scores differed significantly between the restraint groups $(F(1,64)=129.6, p<0.01)$. Independent samples $t$-tests failed to find group differences in BMI, cravings, racial/ethnic background, and hunger ratings (all ps >0.05).

\section{Flanker paradigm}

Analyses were conducted to determine whether participants' responses to the target cues were differentially affected by the flankers. These analyses revealed a main effect of the target picture on response time $\left(F(1,54)=80.7, p<0.001, \eta^{2}=0.55\right)$, indicating overall slower response times for the high calorie target pictures $(627.6 \pm 9.6 \mathrm{~ms})$ compared to the low calorie target pictures $(600.6 \pm 9.1 \mathrm{~ms})$. No other main effects or interactions were significant.

Because Papies et al. (2008) found that restrained eaters demonstrated attentional biases only after they were exposed to food words, it seemed plausible to consider the first block of trials as a food pre-exposure condition because it consisted of presentations that varied in caloric content and palatability. When the first block was excluded from analysis a main effect emerged for the target picture $\left(F(1,64)=55.2, p<0.001, \eta^{2}=0.46\right)$, with response times for the high calorie targets $(605.2 \pm 9.3 \mathrm{~ms})$ significantly slower than those for the low calorie target $(581.6 \pm 9.2 \mathrm{~ms})$, but no other effects reached significance.

\section{Discussion}

The results of the current experiment failed to demonstrate significant differences between the reaction times for the restrained and unrestrained eaters as a function of the caloric content of the targets and flankers. It is possible that because we fed the participants prior to the flanker task, they were not motivated by the 
Table 1

Participant characteristics.

\begin{tabular}{|c|c|c|c|c|}
\hline & \multicolumn{2}{|l|}{ Experiment 1} & \multicolumn{2}{|l|}{ Experiment 2} \\
\hline & Restrained $(n=29)$ & Unrestrained ( $n=37)$ & Restrained $(n=27)$ & Unrestrained $(n=46)$ \\
\hline Age (years) & $19.2 \pm 0.3$ & $19.2 \pm 0.4$ & $19.7 \pm 0.3$ & $19.1 \pm 0.2$ \\
\hline BMI $\left(\mathrm{kg} / \mathrm{m}^{2}\right)$ & $23.1 \pm 0.6$ & $21.6 \pm 0.7$ & $23.9 \pm 0.5$ & $22.9 \pm 0.7$ \\
\hline \multicolumn{5}{|l|}{ Three factor eating questionnaire: } \\
\hline Restraint (Range: 0-21) & $14.3 \pm 0.6$ & $5.9 \pm 0.4^{* *}$ & $16.1 \pm 0.6$ & $6.4 \pm 0.5^{* *}$ \\
\hline Disinhibition (Range: 0-16) & $6.1 \pm 0.5$ & $6.1 \pm 0.6$ & $5.2 \pm 0.5$ & $6.1 \pm 0.4$ \\
\hline Hunger susceptibility (Range: $0-14$ ) & $4.3 \pm 0.5$ & $4.8 \pm 0.5$ & $3.5 \pm 0.5$ & $5.0 \pm 0.4^{*}$ \\
\hline Time since last ate $(\mathrm{h})$ & $N / A^{a}$ & $\mathrm{~N} / \mathrm{A}$ & $10.9 \pm 0.9$ & $10.2 \pm 0.6$ \\
\hline Hunger rating $(1-7)$ & $2.5 \pm 0.2$ & $2.4 \pm 0.3$ & $3.2 \pm 0.3$ & $4.2 \pm 0.2^{*}$ \\
\hline Food Neophobia (Range: 10-70) & $33.5 \pm 2.2$ & $31.5 \pm 2.4$ & $28.1 \pm 1.9$ & $30.3 \pm 1.7$ \\
\hline
\end{tabular}

${ }^{*} p<0.05,{ }^{*} p<0.01$ relative to restrained eaters.

a All participants were fed 20 min before starting the flanker task.

caloric content of the pictures presented. This contention is supported by work conducted by Mogg, Bradley, Hyare, and Lee (1998) who found that hunger is crucial for selective attention to food words. Therefore, in the second experiment, we recruited another sample of female undergraduates, who were scheduled to participate in the study at the same time of day as in the first experiment. As before, we asked participants not to eat for at least $2 \mathrm{~h}$ before coming to the lab, and we did not feed them prior to completing the flanker task. We hypothesized that hunger would potentiate attentional bias in these hungry participants, however, restrained eaters would be more distracted by high than low calorie flankers while completing the task relative to unrestrained eaters.

\section{Experiment 2}

\section{Method}

\section{Participants}

The participants $(N=105)$ were undergraduate female students of the College of William \& Mary, Virginia, USA. Almost a third (i.e., $30 \%$ ) had been recruited through flyers posted on campus and paid $\$ 10$ for their participation between the spring and fall of 2011. The remaining students were taking Introduction to Psychology classes and received credit for their participation. In order to ensure the participants were hungry, they were asked to refrain from eating for at least $2 \mathrm{~h}$ before arriving at the lab for their scheduled appointment.

\section{Procedure}

After completion of the informed consent procedure, participants were asked to complete a demographics questionnaire. They were then taken to another room where they rated their hunger and completed the flanker task as in Experiment 1. Questionnaires covering food and eating behavior explicitly (TFEQ and FN) were completed after the flanker task, as was measurement of height and weight. On average the entire procedure took $50 \mathrm{~min}$ to complete.

\section{Results and discussion}

\section{Participant characteristics}

Participânts who had food allergies $(n=14)$, were vegetarian $(n=6)$, restricted only red meat or pork from their diet $(n=3)$, and those who reported eating within the previous $2 \mathrm{~h}(n=9)$ were excluded from the analyses. The ethnic background of the remaining 73 participants was $9.0 \%$ Hispanic or Latino, and their racial background was $65.7 \%$ White, 13.4\% African American, 10.5\% Asian and $10.4 \%$ other. Participants were on average $19.3( \pm 0.1)$ years old and had a BMI of $22.8( \pm 0.4)$. Based on their scores on the restrained eating scale, participants were divided into restrained $(n=27)$ and unrestrained $(n=46)$ groups in the manner as described in Experiment 1. As shown in Table 1, the mean restraint scores differed significantly between the restraint $(F(71)=145.0$, $\left.p<0.001, \eta^{2}=0.67\right)$ groups, as did scores on the hunger rating scale $\left(F(71)=7.4, p<0.01, \eta^{2}=0.09\right)$, and hunger susceptibility on the TFEQ $\left(F(71)=5.8, p<0.02, \eta^{2}=0.08\right)$, with restrained eaters reporting lower scores than unrestrained eaters for current hunger and hunger susceptibility. However, there were no group differences in Food Neophobia, BMI, or the amount of time since the participants ate last, which for both groups was approximately $10 \mathrm{~h}$ before the session (all $p$ s >0.05).

\section{Flanker task}

Because the restraint groups differed in their ratings of hunger, we conducted a mixed factorial ANCOVA, which included the same within- and between-subjects factors as in Experiment 1, as well as hunger rating as a covariate. This analysis revealed a target $\times$ flanker $\times$ restraint group interaction $(F(1,70)=3.9, p=0.05$ $\left.\eta^{2}=0.05\right)$. As shown in Fig. $1 \mathrm{~A}$, the unrestrained eaters appeared to respond slower to the high calorie targets overall, and to the presence of high calorie flankers overall. These observations were supported by a main effect of target $(F(1,45)=18.6, p<0.001$, $\left.\eta^{2}=0.29\right)$, and flanker $\left(F(1,45)=11.9, p<0.001, \eta^{2}=0.21\right)$, but no target $\times$ flanker interaction $\left(p>0.30, \eta^{2}=0.01\right)$. In contrast, analyses of the restrained eaters yielded a marginal target $\times$ flanker interaction $\left(F(1,26)=3.4, p=0.07, \eta^{2}=0.12\right)$. As shown in Fig. $1 \mathrm{~B}$, simple main effects analyses revealed that for the low calorie targets only, restrained eaters responded more slowly when they were flanked by high calorie pictures $\left(F(1,26)=5.6, p<0.03, \eta^{2}=0.18\right)$. The restrained eaters' reaction times to the high calorie targets were not affected by the caloric content of the flankers $(p>0.86$, $\left.\eta^{2}<0.01\right)$.

These findings suggest that when hungry, female restrained and unrestrained eaters experienced more conflict when presented with high than low calorie flanker pictures. For restrained eaters, attentional biases occurred only when low calorie targets were flanked by high calorie pictures, whereas for unrestrained eaters reaction times to both high and low calorie targets was slowed by high calorie flankers.

\section{General discussion}

The goal of the present study was to determine whether restrained eaters demonstrated selective attention to high calorie picture cues using a flanker paradigm, an implicit behavioral task. When individuals were not hungry in Experiment 1, the presênce of high calorie distractors had very little effect on performance, 


\section{A. Unrestrained Eaters}

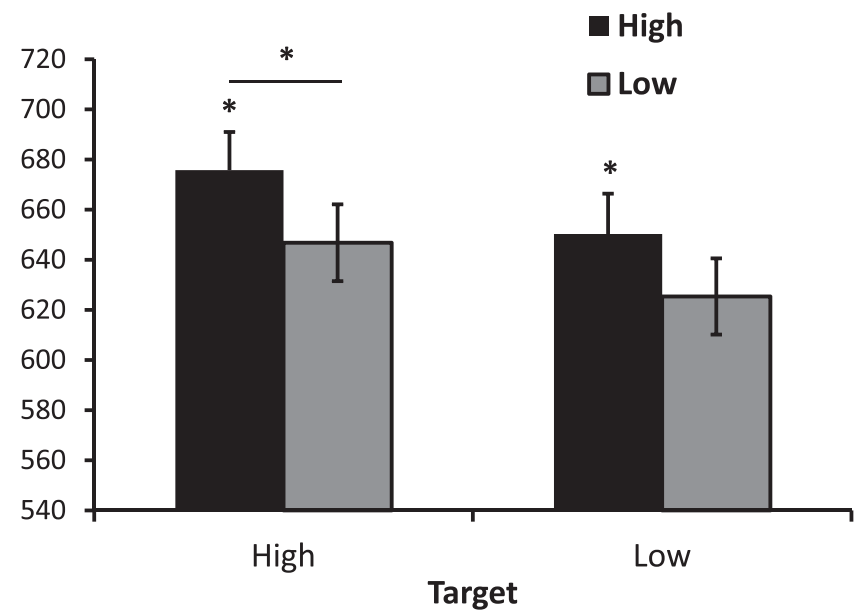

B. Restrained Eaters

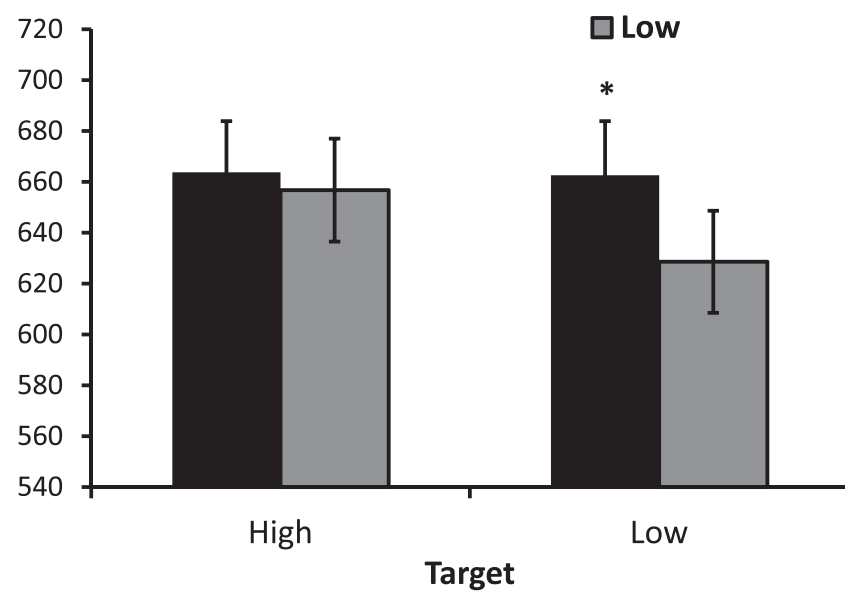

Fig. 1. Estimated marginal means of unrestrained and restrained eaters' reaction times to the high and low calorie food targets that were presented with high (black bars) and low (grey bars) calorie food cue flankers (*indicates significantly longer reaction times, $p<0.05$ ).

who are hungry are processing the caloric value of foods, and their attention to low calorie targets is drawn away by the presence of high calorie flankers. Within the context of understanding attentional bias to foods, this task has ecological validity in that Western society is marked by a dense display of foods in advertisements and restaurants from which consumers must choose. This validity is further enhanced through the use of pictures rather than words in this paradigm. This has been demonstrated in previous research with smokers which revealed that pictures trigger better responses than words (Huijding \& de Jong, 2006; Huijding, de Jong, Wiers, \& Verkooijen, 2005).

From a cognitive psychological perspective, these findings contrast with findings typically reported in flanker tasks which have traditionally consisted of arrays of stimuli devoid of motivational significance, such as strings of letters (e.g., FFHFF) or arrowheads (e.g., $>><>>$ ). In each of the trials the central target is flanked by peripheral stimuli that either activate the same response as the target (compatible trials) or an opposing response (incompatible trials; e.g., Coles et al., 1985; Gratton, Coles, \& Donchin, 1992). Typically, when presented with such stimuli, participants respond more slowly on incompatible relative to compatible trials because the target and the peripheral flanker stimuli induce opposing responses. However, the present study demonstrates that this finding is not necessarily generalizable to motivationally relevant stimuli. Rather in this study, flankers interfere with participants' responses to varying degrees depending on their biological state (i.e., whether or not they are hungry) and their cognitive restraint.

Although not manipulated within a single experiment, the preliminary finding that hungry but not fed participants were distracted by the high calorie food flankers is consistent with previous work which also demonstrated that hunger is associated with a bias in attention for stimuli that are relevant to the motivational state (Mogg et al., 1998). Together these findings support incentive salience theory, which contends that cues associated with rewards become sensitized; that is, they acquire the ability to engage the same brain systems as the rewards themselves (Robinson \& Berridge, 1993). Research has shown that sensitization to rewarding stimuli, such as high calorie, palatable foods, or addictive substances may increase the allocation of attentional resources to these stimuli, thereby enhancing cue-related cognitions and diminishing the attentional resources available for alternative cues. In this manner, hunger or food craving may become reciprocally associated with the enhanced attentional processing of the desired stimulus (Franken, 2003), which, in turn, may motivate or increase intake. Accordingly, with respect to food, it has been-suggested that greater incentive salience and anticipation of reward might foster weight gain and subsequent attempts to restrict food intake in restrained eaters (Lowe \& Kral, 2006; Stice, Cooper, Dale, Tappe, \& Q4 Lowe, 2010).

That restrained eaters demonstrated an attentional bias only when they were hungry may be surprising, given that in situations of relative satiety they are believed to be susceptible to overconsumption of palatable foods. Often such disinhibited eating is reported in response to particular challenges to their diet (such as a high calorie pre-load; Herman \& Mack, 1975; Mills \& Palandra, 2008), an emotional challenge (such as watching a scary movie; Cools, Schotte, \& Mcnally, 1992), or distraction by another cognitive task (e.g., Ward \& Mann, 2000). However, although participants were fed before engaging in the flanker task in Experiment 1 , the food provided would not be considered high calorie, nor would the flanker task be interpreted as either emotionally arousing or cognitively taxing.

Lowe and Kral (2006) has suggested that because restrained eating might reflect a tendency to eat less than one wants, rather than less than one needs, restrained eaters who are not biologically hungry may nonetheless feel deprived because the food environment 
creates frequent temptations to eat what they are constantly trying to resist. Thus, restrained eaters are in a constant state of hedonic (wanting more palatable foods) rather than homeostatic hunger (i.e., biological hunger). If this is the case, then the results of the current work suggest that the attentional bias, which is observed only when participants are hungry, is at least partially driven by homeostatic hunger. The effects of hedonic hunger may also be demonstrated by the fact that for restrained eaters, high calorie cues, which are typically highly palatable and desired, drew attention away only from the low calorie, less palatable targets. These findings suggest that for these individuals, who continually strive to restrict their weight by eating low calorie foods, attention is readily distracted from "responsible" lower calorie food choices to highly desired but forbidden foods that are high in calories. This is further supported by previous research which reports that attentional bias to food cues increases with perceived hedonic ratings of those foods in restrained eaters (Papies et al., 2008).

It is also important to note that although the findings of the current study are in contrast to those reported by Meule et al. (2012), there were important differences in the methodological procedures employed. In Meule et al., participants were asked to categorize target pictures, which depicted either a high calorie food or a household non-food item and were flanked by pictures from each of these categories. Given that Meule et al. used pictures of items from different categories (i.e., foods vs. household items), whereas in this study both the targets and flankers were from the same taxonomic category (i.e., foods), it is not surprising that the reaction times of our participants were approximately $200 \mathrm{~ms}$ slower than those in Meule et al. It is likely that distinguishing between foods to determine whether they fell into a particular sub-category was more cognitively challenging than determining whether an item is a food item or not. Although the restrained eaters in the Meule et al. study did not differ from the unrestrained eaters in their ability to resist the high calorie distractors, restrained eaters showed shorter reaction times to high calorie targets (regardless of the flanker) than unrestrained eaters. Taken together, the results of our study and that of Meule et al. suggest that high calorie flankers may more effectively distract attention from other food items than items from other categories.

Although the explicit task in the present study was to categorize foods into breakfast and non-breakfast food items, a task that had seemingly little to do with the caloric content of the target or flanker items per se, participants may have considered the caloric content of the target foods as they decided whether they would consume these foods for breakfast themselves. This question was chosen because of its similarity to decisions that individuals make every day as they choose food to eat for specific meals or snacks. Despite the ecological validity of the present task, it was not completely irrelevant to caloric content of the target and distractors, as the task required participants to think about properties of the food stimuli. Future research should examine whether a completely stimulus-irrelevant categorical task would also result in differential implicit categorization of high and low calorie foods by restrained and unrestrained eaters, as this would provide a more stringent test of the ability of the flankers to distract attention away from the target cues. Moreover, it is possible that some participants may have been unsure whether they would eat some foods for breakfast. However, this would have added variability to our data, thereby reducing our chances of observing evidence of attentional bias as we did in Experiment 2. Finally, like much of the research conducted in this area, these findings are generalizable only to college age women, given the characteristics of our sample. Further research should focus on other demographic groups such as men and older participants.

To our knowledge, this is the first experimental report that demonstrates differential levels of attentional bias in restrained and unrestrained eaters using the flanker task. These findings replicate and extend previous reports that have used other tasks such as the Stroop task (e.g., Stewart \& Samoluk, 1997), and help explain apparent inconsistencies in this work that may have occurred because of the variety of methodologies used and differences in stimuli across studies. The current findings suggest that chronic dietary restraint is associated with an increased tendency to direct attention away from low calorie food choices specifically, and towards unhealthful food-related cues. Thus when presented with an array of food options that vary in nutritional and caloric content, restrained eaters' focus on one or two high calorie options may prevent them from noticing other options that may provide more nutrition or fewer calories. Although unrestrained eaters' attention was also slowed by high calorie flankers, they demonstrated relatively equivalent response conflict in the HLH and HHH conditions.

In conclusion, although the current results should be considered preliminary until further investigations using the flanker task can support their generalizability and manipulate hunger directly, they provide initial evidence that high calorie foods induce response conflict differentially in restrained and unrestrained eaters. Future research should determine whether differences in attentional bias to high and low calorie foods leads to differential consumption of these foods. Given that Americans spend approximately $\$ 33$ billion dollars on diet products and services each year (Cleland et al., 2001 ) but frequently fail to lose weight (Garner \& Wooley, 1991), it is important to understand the mechanisms involved in food choice decisions. Such an understanding will have important health-related implications by leading to more targeted strategies to prevent unhealthful eating and subsequent weight gain.

\section{Uncited references}

Herman and Polivy (1980), Lattimore et al. (2000), Stunkard and Messick (1988), and White et al. (2002).

\section{References}

Ahern, A. L., Field, M., Yokum, S., Bohon, C., \& Stice, E. (2010). Relation of dietary restraint scores to cognitive biases and reward sensitivity. Appetite, 55, 61-68.

Boon, B., Vogelzang, L., \& Jansen, A. (2000). Do restrained eaters show attention toward or away from food, shape and weight stimuli? European Eating Disorders Review, 8, 51-58.

Botvinick, M., Braver, T. S., \& Barch, D. M. (2001). Conflict monitoring and cognitive control. Psychological Review, 108, 624-652.

Centers for disease control and prevention. (2009). Obesity Halting the Epidemic by Making Health Easier. National Center for Chronic Disease Prevention and Health Promotion. Available from http://www.cdc.gov/chronicdisease/resources/ publications/AAG/obesity.htm.

Cleland, R., Graybill, D. C., Hubbard, V., Kahn, L. K., Stern, J. S., Wadden, T. A. Weinsier, R., Yanovski, S., Gross, W. C., \& Daynard, M. (2001). Commercia weight loss products and programs. What consumers stand to gain and lose. A public conference on the information consumers need to evaluate weight loss products and programs. Critical Review of Food Science and Nutrition, 41, 45-70.

Coles, M. G., Gratton, G., Bashore, T. R., Eriksen, C. W., \& Donchin, E. (1985). A psychophysiological investigation of the continuous flow model of human information processing. Journal of Experimental Psychology. Human Perception and Performance, 11, 529-553.

Cools, J., Schotte, D. E., \& Mcnally, R. J. (1992). Emotional arousal and overeating in restrained eaters. Journal of Abnormal Psychology, 101, 348-351. doi: 10.1037| 0021-843X.101.2.348.

Dickter, C. L., \& Bartholow, B. D. (2007). Racial ingroup and outgroup attention biases revealed by event-related brain potentials. Social Cognition and Affective Neuroscience, 2, 189-198.

Eriksen, B. A., \& Eriksen, C. W. (1974). Effects of noise letters upon the identification of a target letter in a nonsearch task. Perception \& Psychophysics, 16(1), 143-149.

Flegal, K. M., Carroll, M. D., Ogden, C. L., \& Curtin, L. R. (2010). Prevalence and trends in obesity among US adults, 1999-2008. Journal of the American Medical Association, 303, 235-241. doi: 10.1001/jama.2009.2014.

Franken, I. H. (2003). Drug craving and addiction. Integrating psychological and neuropsychopharmacological approaches. Progress in NeuroPsychopharmacology E Biological Psychiatry, 27(4), 563-579.

Garner, D. M., \& Wooley, S. C. (1991). Confronting the failure of behavioral and dietary treatments for obesity. Clinincal Psychology Review, 11, 729-780. doi: 10.1016/0272-7358(91)90128-H. 
Gratton, G., Coles, M. G. H., \& Donchin, E. (1992). Optimizing the use of information. Strategic control of activation of responses. Journal of Experimental Psychology, General, 121, 480-506.

Herman, C. P., \& Mack, D. (1975). Restrained and unrestrained eating. Journal of Personality, 43(4), 647-660.

Herman, C. P., \& Polivy, J. (1975). Anxiety, restraint, and eating behavior. Journal of Abnormal Psychology, 84(6), 666-672.

Herman, C. P., \& Polivy, J. (1980). Restrained eating. In A. Stunkard (Ed.), Obesity (pp. 208-225). Philadelphia, PA: W.B. Saunders.

Hollitt, S., Kemps, E., Tiggemann, M., Smeets, E., \& Mills, J. S. (2010). Components of attentional bias for food cues among restrained eaters. Appetite, 54, 309-313.

Huijding, J., \& de Jong, P. J. (2006). Automatic associations with the sensory aspects of smoking. Positive in habitual smokers but negative in non-smokers. Addictive Behaviors, 31(1), 182-186.

Huijding, J., de Jong, P. J., Wiers, R. W., \& Verkooijen, K. (2005). Implicit and explicit attitudes toward smoking in a smoking and a nonsmoking setting. Addictive Behaviors, 30(5), 949-961.

Ito, T. A., \& Cacioppo, J. T. (2000). Electrophysiologial evidence of implicit and explicit categorization processes. Journal of Experimental Social Psychology, 36, 660-676. doi:10.1006/jesp.2000.1430.

Lattimore, P. J., Thompson, G. M., \& Halford, J. C. (2000). Developmental onset of eating related color naming interference. The role of restraint and eating psychopathology. International Journal of Eating Disorders, 28, 2732.

Lowe, M. R., \& Kral, T. V. E. (2006). Stress-induced eating in restrained eaters may not be caused by stress or restraint. Appetite, 46, 16 21. doi: 10.1016 t j.appet.2005.01.014.

Meule, A., Vögele, C., \& Kübler, A. (2012). Restrained eating is related to accelerated reaction to high caloric foods and autonomic dysregulation. Appetite, 58, 638-644. doi:10.1016/j.appet.2011.11.023.

Mills, J. S., \& Palandra, A. (2008). Perceived caloric content of a preload and disinhibition among restrained eaters. Appetite, 50, 240-245.

Mogg, K., Bradley, B. P., Hyare, H., \& Lee, S. (1998). Selective attention to foodrelated stimuli in hunger. Are attentional biases specific to emotional and psychopathological states, or are they also found in normal drive states? Behaviour Research and Therapy, 36(2), 227-237.

Papies, E. K., Stroebe, W., \& Aarts, H. (2008). The allure of forbidden food. On the role of attention in self-regulation. Journal of Experimental Social Psychology, 44, $1283-1292$.
Pliner, P., \& Hobden, K. (1992). Development of a scale to measure the trait of food neophobia in humans. Appetite, 19, 105-120.

Robinson, T. E., \& Berridge, K. C. (1993). The neural basis of drug craving. An incentive-sensitization theory of addiction. Brain Research Reviews, 18, 247-291. doi: 10.1016/0165-0173(93)90013-P.

Stewart, S. H., \& Samoluk, S. B. (1997). Effects of short-term food deprivation and chronic dietary restraint on the selective processing of appetitve-related cues. International Journal of Eating Disorders, 21(2), 129-135.

Stice, E., Cooper, J. A., Dale Tappe, K., \& Lowe, M. R. (2010). Are dietary restraint 0 scales valid meastres of moderate to long term dietary restriction? Objective biological and behavioral data suggest not. Psychological Assessment, 19, 09 449-458. doi: $10.1037 / 1040-3590.19 .4 .449$.

Stroebe, W. (2008). Dieting, overweight, and obesity. Self-regulation in a food-rich environment. Washington, DC: American Psychological Association.

Stunkard, A., \& Messick, S. (1985). The three-factor eating questionnaire to measure dietary restraint, disinhibition, and hunger. Journal of Psychosomatic Research, 29, 71-83. doi:10.1016/0022-3999(85)90010-8.

Stunkard, A., \& Messick, S. (1988). Eating inventory. Manual. San Diego, CA: Psychological Coropration, Harcourt Brace Jovanovich.

U.S. Department of Health and Human Services. (2004). The Surgeon General's call to action to prevent and decrease overweight and obesity. U.S. Department of Health and Human Services. Available from http://www.surgeongeneral.gov/ topics/obesity/calltoaction/toc.htm.

Ward, A., \& Mann, T. (2000). Don't mind if I do. Disinhibited eating under cognitive load. Journal of Personality and Social Psychology, 78, 753-763.

Wegner, D. M. (1994). Ironic processes of mental control. Psychology Review, 1, 34-52.

Westenhoefer, J., Broeckmann, P., Münch, A.-K., \& Pudel, V. (1994). Cognitive control of eating behavior and the disinhibition effect. Appetite, 23, 27-41.

White, M. A., Whisenhunt, B. L., Williamson, D. A., Greenway, F. L., \& Netemeyer, R G. (2002). Development and validation of the food-craving inventory. Obesity Research, 10, 107 114.

Williamson, D. F., Serdula, M. K., Anda, R. F., Levy, A., \& Byers, T. (1992). Weight loss attempts in adults. Goals, duration, and rate of weight loss. American Journal of Public Health, 82, 1251-1257. 